\title{
AVALIAÇÃO DE PARÂMETROS FÍSICOS E QUÍMICOS PARA A PRODUÇÃO DE ARGAMASSAS UTILIZANDO CINZA VOLANTE E RESÍDUO DA CONSTRUÇÃO CIVIL
}

\author{
K. C. FERREIRA ${ }^{1}$, S. G. e GONÇALVES ${ }^{1}$, D.N.P CARDOSO ${ }^{1}$, J. A. da S. SOUZA ${ }^{2}$, \\ A.M.P.F. FELIPE ${ }^{2}$ \\ ${ }^{1}$ Universidade Federal do Pará, Programa de Pós-Graduação em Engenharia Química \\ ${ }^{2}$ Universidade federal do Pará, Faculdade de Engenharia Química \\ E-mail para contato: keyllafcastro@yahoo.com.br
}

\begin{abstract}
RESUMO - Considerada uma das principais atividades geradoras de desenvolvimento econômico e social, o setor da construção civil é também o responsável por uma série de impactos ambientais, entre eles a geração de resíduos/entulho constituído principalmente por silicoaluminatos com características de elevado teor de sílica e alumina, isolados. Neste trabalho, o rejeito da construção civil foi utilizado como agregado miúdo em mistura com cinza volante (resíduo de carvão mineral) e cimento Portland, para a produção de argamassas. O resíduo da construção civil foi submetido à caracterização mineralógica e físico-química e a cinza volante foi caracterizada pela análise de espectrofotometria de raios-X e granulométrica. Para produção das argamassas formularam-se quatro composições de RCC nas proporções de 95, 90, 85 e 80\%, CV de 0, 5, 10 e $15 \%$ e 5\% de cimento Portland CP II Z 32. Após a cura de 28 dias os corpos de prova foram submetidos a ensaios físicos: absorção, porosidade e massa específica; ensaio de resistência à compressão e análise de difratometria de raios-, os resultados mostraram que o traço 3 e traço 4 apresentaram melhores resultados de resistência mecânica, comprovando a viabilidade da utilização do rejeito da construção civil e cinza volante na produção de argamassas.
\end{abstract}

\section{INTRODUÇÃO}

Atualmente diversas formas de resíduos industriais estão sendo estudados e pesquisados, como alternativa para serem incorporados à indústria da construção civil, oferecendo grande potencial para solucionar problemas do acúmulo do resíduo no meio ambiente, assim como a diminuição dos custos finais, como a incorporação de cinza volante, objetivo deste estudo (CURTIUS e FIEDLER, 2002).

Um dos principais desafios propostos por essa indústria é aumentar a durabilidade de seus produtos, sendo assim nos materiais fabricados a partir do cimento Portland, essa substituição pode ser feita de forma parcial substituindo o clínque Portland pela adição de minerais. Essas adições fazem com que ocorram significativas modificações, ocasionando mudanças nas características do estado fresco e no estado endurecido, como também em sua microestrutura (POZZOBON, 1999). 
Os resíduos de construção civil apresentam em sua composição mineralógica: silicoaluminatos, óxidos de ferro e titânio e carbonatos (FERREIRA, 2014). A cinza volante é um resíduo industrial resultante da combustão do carvão mineral em caldeiras de leitos fluidizados. Estes dois resíduos podem formar uma importante matéria prima para a produção de argamassas destinadas a varias aplicações como: assentamentos de pisos, reboco e nivelamento de paredes, formação de contra pisos, etc.

$\mathrm{Na}$ tentativa de contribuir com o aumento no conhecimento sobre a produção de argamassas e de sugerir uma forma de destino aos resíduos de construção civil e resíduos oriundos da indústria de mineração e metalurgia, este trabalho foi desenvolvido com a idéia de maximizar a utilização dos resíduos (construção e cinza) e minimizar o uso de cimento Portland na produção de argamassas para a indústria da construção civil.

\section{MATERIAS E MÉTODOS}

Neste trabalho foram utilizados Resíduos de Construção Civil (RCC); Cinzas Volantes (CV) e Cimento Portland Comum (CP II Z 32).

Os RCC foram coletados na UFPA e foram provenientes da reforma do laboratório de Engenharia Química (LEQ). O material coletado passou por processos de operações unitária de acordo com a norma ABNT NBR 7217. Todo o material separado (alvenaria e reboco) foi britado e moído com moinho de disco MARCONI Modelo MA700 série (100690037); Moinho de bolas CIMAQ S.A Modelo Work Index série (005) e classificado em peneiras a fim da amostra de agregado miúdo reciclado obedecer aos requisitos da norma ABNT NBR 7211.

A cinza volante, usada foi proveniente da refinaria de alumina Hydro, localizada no município de Barcarena-Pa. A sua produção ocorre em caldeiras de leito fluidizado circulante a partir da combustão do carvão mineral. O cimento Portland utilizado foi classificado como tipo CP II - E 32, conforme a norma ABNT NBR11578/1991.

A caracterização do resíduo foi feita através das análises química e mineralógica as quais são: e difração de raios-X. A cinza volante foi caracterizada pela análise de espectrometria de fluorescência de raios-X e granulométrica.

Para a confecção dos corpos de prova (Erro! Fonte de referência não encontrada.) utilizou-se fôrmas cilíndricas de policloreto de vinila (PVC) com dimensões de $10 \mathrm{~cm}$ de altura e $5 \mathrm{~cm}$ de diâmetro. As proporções utilizadas e descritas na Erro! Fonte de referência não encontrada. para a composição dos corpos de prova foram baseadas de acordo com Carvalho et al. (2013) para a confecção dos corpos de prova. Foram produzidas seis amostras (sextuplicata) de cada traço, sendo produzida uma argamassa de referência (sem adição de cinza) para comparação com argamassas adicionadas de cinzas de carvão mineral em substituição ao cimento. Os traços foram submetidos ao tempo de cura que foi de 28 dias para posteriormente as amostras serem ensaiadas. 


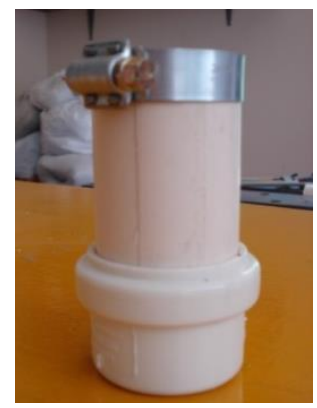

Figura1 - Forma em PVC.

Tabela 1 - Composição dos corpos de prova

\begin{tabular}{cccc}
\hline TRAÇOS & $\begin{array}{c}\text { REJEITO } \\
(\boldsymbol{\%})\end{array}$ & $\begin{array}{c}\text { CIMENTO } \\
(\boldsymbol{\%})\end{array}$ & $\begin{array}{c}\text { CINZA } \\
(\boldsymbol{\%})\end{array}$ \\
\hline $\operatorname{Tr} 1$ & 95 & 5 & 0 \\
$\operatorname{Tr} 2$ & 90 & 5 & 5 \\
$\operatorname{Tr} 3$ & 85 & 5 & 10 \\
$\operatorname{Tr} 4$ & 80 & 5 & 15 \\
\hline
\end{tabular}

Após o tempo de cura dos corpos de prova de argamassa, foram executados os ensaios físicos-mecânico de absorção e porosidade segundo a ABNT NBR 9778, massa específica segundo ABNT NBR 13280 e resistência à compressão segundo ABNT 7215, para avaliar as propriedades cerâmicas e verificar como se comportavam com diferentes teores de cinza volante e análises de difração de raios-X e microscopia eletrônica de varredura para identificar a formação dos cristais de alita e belita e assim confirmar a atividade pozolânica da cinza volante.

\section{RESULTADOS E DISCUSSÕES}

\subsection{Caracterização dos resíduos}

Resíduo da construção civil: A Figura 2 representa a caracterização da amostra por difração de raios $-X$. Esta análise foi utilizada para identificar as fases mineralógicas dos principais compostos do resíduo de construção civil. De acordo com as intensidades das raias de difração, verifica-se que, dos compostos cristalinos, o quartzo é mais frequente, o que caracteriza o rejeito de construção civil como um dos materiais constituintes da argamassa. 


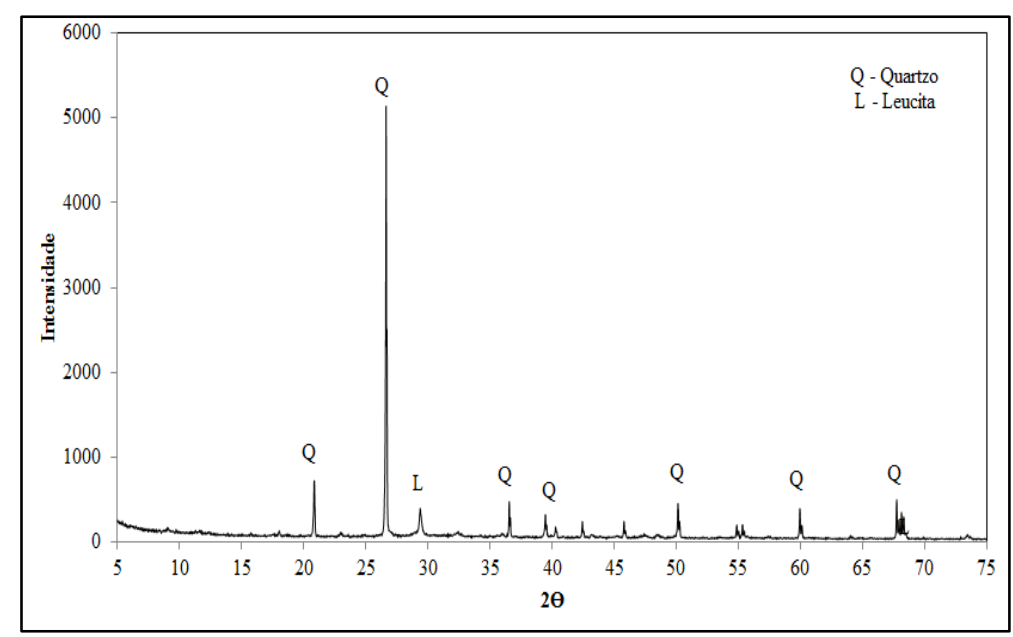

Figura 2 - Difratograma do RCC.

A Tabela apresenta os teores de óxidos encontrados no RCC. Observou-se que o RCC é composto em sua maioria $(95,11 \%)$ por óxidos de silício, e em sua minoria por óxidos de alumínio $(0,57 \%)$, ferro $(0,31 \%)$ e potássio $(0,17 \%)$ o que o caracteriza como um bom agregado miúdo para produção de argamassas. $\mathrm{O}$ alto teor de óxido de silício $\left(\mathrm{SiO}_{2}\right)$ encontrado deve está associado, principalmente, aos agregados naturais do concreto e da argamassa de paredes presentes no RCC.

Tabela 2 - Composição química do RCC.

\begin{tabular}{cc}
\hline ELEMENTOS & TEOR** $(\%)$ \\
\hline $\mathrm{SiO}_{2}$ & 95,11 \\
$\mathrm{Al}_{2} \mathrm{O}_{3}$ & 0,57 \\
$\mathrm{Fe}_{2} \mathrm{O}_{3}$ & 0,31 \\
$\mathrm{~K}_{2} \mathrm{O}$ & 0,17 \\
$\mathrm{PF}^{*}$ & 3,84 \\
\hline
\end{tabular}

*Perda ao fogo

Cinza volante: Na Tabela abaixo são apresentados à composição química da cinza do carvão mineral, obtidas a partir da análise de espectrofotometria de raios $-\mathrm{X}$. A análise química de fluorescência de raios -X mostrou que a cinza volante contém em sua composição química vários óxidos, sendo em maiores proporções os óxidos de alumínio, sílica e cálcio, os quais possuem pouco ou nenhum valor cimentante, mais que na forma finamente dividida e na presença de umidade reage quimicamente com hidróxido de cálcio para formar componentes que possuem propriedades cimentantes, o que caracteriza a cinza volante como pozolana.

Tabela 3 - Composição química da CV.

\begin{tabular}{cc}
\hline ELEMENTOS & TEOR (\%) \\
\hline $\mathrm{Na}_{2} \mathrm{O}$ & 0,941 \\
$\mathrm{MgO}$ & 1,836 \\
$\mathrm{Al}_{2} \mathrm{O}_{3}$ & 16,399 \\
\hline
\end{tabular}




\begin{tabular}{cc}
\hline $\mathrm{SiO}_{2}$ & 42,53 \\
$\mathrm{P}_{2} \mathrm{O}_{5}$ & 0,194 \\
$\mathrm{~S}$ & - \\
$\mathrm{K}_{2} \mathrm{O}$ & 1,61 \\
$\mathrm{CaO}$ & 19,005 \\
$\mathrm{TiO}_{2}$ & 0,897 \\
$\mathrm{MnO} \mathrm{Fe}_{2}$ & 0,073 \\
$\mathrm{PF}_{3}$ & 7,081 \\
$\mathrm{Cr}^{*} \mathrm{Orânico}_{\mathrm{CO}_{2} \text { total }}$ & - \\
$\mathrm{Cl}(\mathrm{ppm})$ & - \\
$\mathrm{SO}$ & 0,056 \\
$\mathrm{ZnO}$ & 9,208 \\
$\mathrm{Rb}$ & 0,014 \\
$\mathrm{SrO}$ & 0,011 \\
$\mathrm{BaO}$ & 0,046 \\
\hline
\end{tabular}

*Perda ao fogo.

Os resultados obtidos na análise granulométrica mostraram que de uma forma geral, as amostras de CV são bastante finas, apresentando em sua maioria partículas com tamanho médio de $0,0804 \mathrm{~mm}$ o que indica que elas podem ser usadas para o preparo das argamassas como mostra a Figura 3.

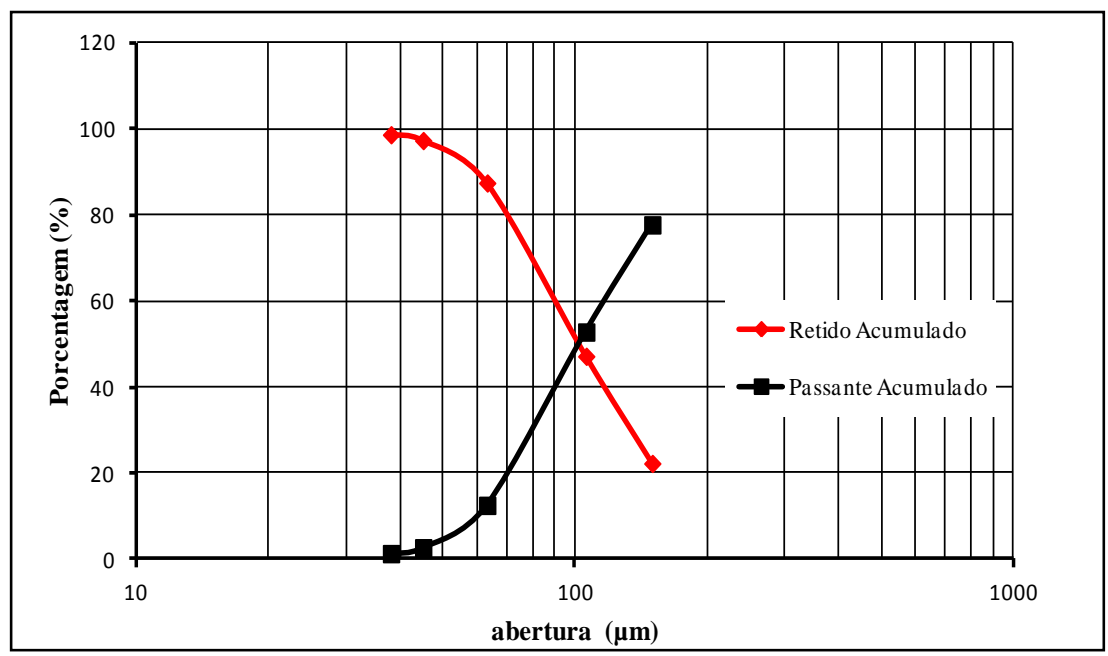

Figura 3 - Análise granulométrica da cinza volante.

Ensaios físicos e mecânico: Na Tabela são apresentados os resultados médios obtidos dos ensaios físicos-mecânico das argamassas em diferentes traços. 
Tabela 4 - Resultados dos ensaios físico-mecânicos.

\begin{tabular}{ccccccc}
\hline $\begin{array}{c}\text { TEOR } \\
\text { REJEITO } \\
(\boldsymbol{\%})\end{array}$ & $\begin{array}{c}\text { TEOR } \\
\text { CINZAS } \\
(\boldsymbol{\%})\end{array}$ & $\begin{array}{c}\text { TEOR } \\
\text { CIMENTO } \\
(\boldsymbol{\%})\end{array}$ & $\begin{array}{c}\text { ABSORÇÃO } \\
(\boldsymbol{\%})\end{array}$ & $\begin{array}{c}\text { POROSIDADE } \\
(\boldsymbol{\%})\end{array}$ & $\begin{array}{c}\text { MASSA } \\
\text { ESPECÍFICA }\end{array}$ & $\begin{array}{c}\text { RESISTÊNCIA À } \\
\text { COMPRESSÃO } \\
(\mathbf{M P a})\end{array}$ \\
\hline 95 & 0 & 5 & 15,65 & 23,48 & 1,50 & 10,49 \\
90 & 5 & 5 & 17,35 & 24,50 & 1,41 & 7,49 \\
85 & 10 & 5 & 20,90 & 29,00 & 1,39 & 6,49 \\
80 & 15 & 5 & 23,30 & 31,34 & 1,35 & 5,74 \\
\hline
\end{tabular}

A partir dos resultados da Tabela 4 produziram-se os gráficos de absorção, porosidade, massa específica aparente e resistência à compressão versus teor de cinzas (Figuras 4).

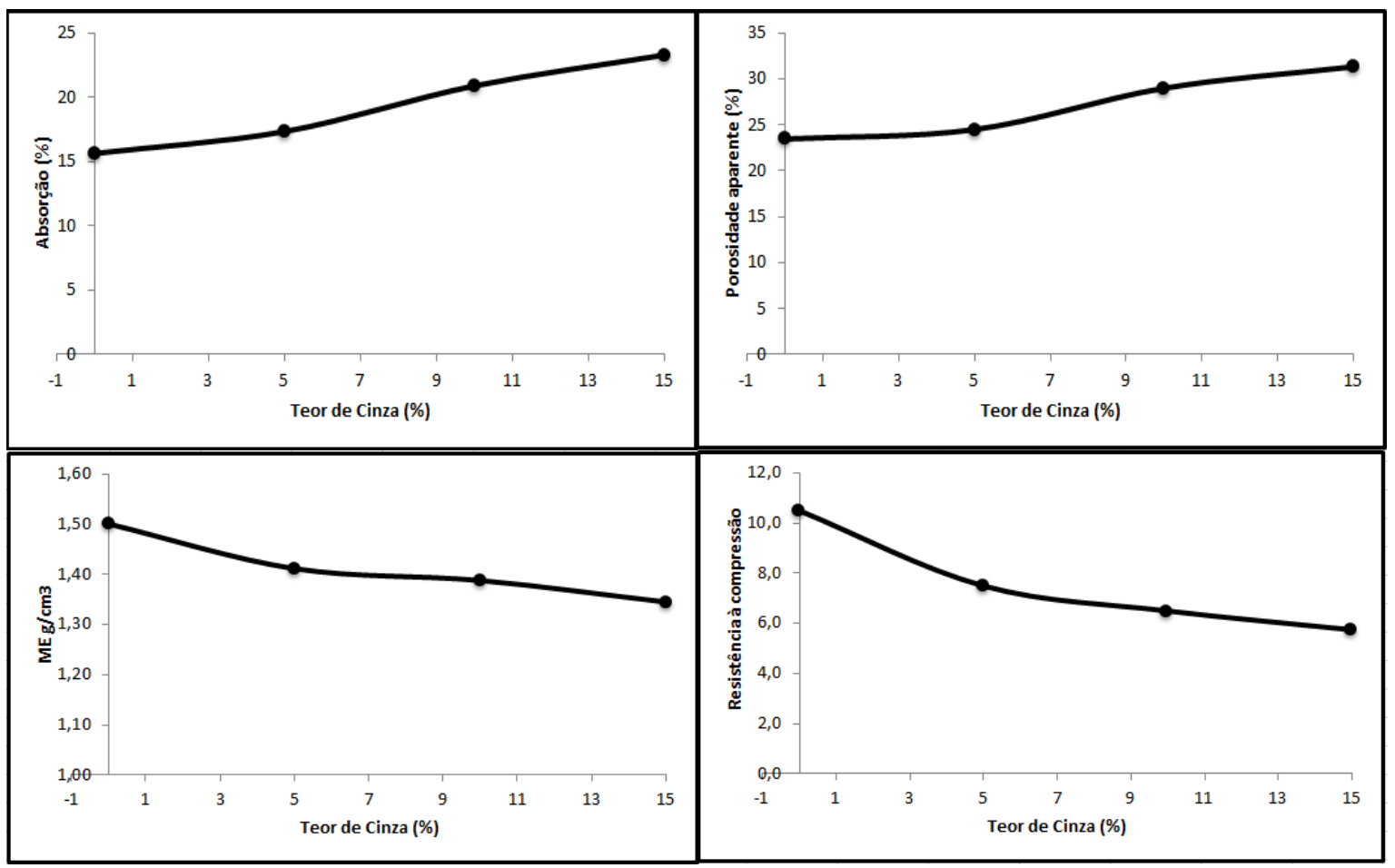

Figura 4 - Absorção, Porosidade, Massa específica e Resistência à compressão das argamassas.

À medida que se aumenta o teor de cinza volante e diminui o teor de cimento ocorre um aumento na porosidade e consequentemente na absorção de água. Segundo Siqueira (2012), isso ocorre devido à redução nos componentes básicos do cimento, como silicatos e aluminatos de cálcio reduzindo a capacidade de cristalização na mistura, pois a ausência desses componentes implica em uma redução das fases cristalinas responsáveis pelo aumento no meio ligante o que deve acontecer também com outras propriedades como a resistência mecânica e a massa especifica que diminuem.

Nos difratrogramas dos traços 1 e 2 com 0 e $5 \%$ de cinza volante é possível observar o início da formação dos picos dos cristais das alitas e belitas, sendo o pico máximo nas composições de 10 e $15 \%$ em peso de cinza volante. Observa-se que nas quatro amostras há 
formação de cristais de belita (B) e alita (A) comprovando que a cinza volante apresenta atividade pozolânica.

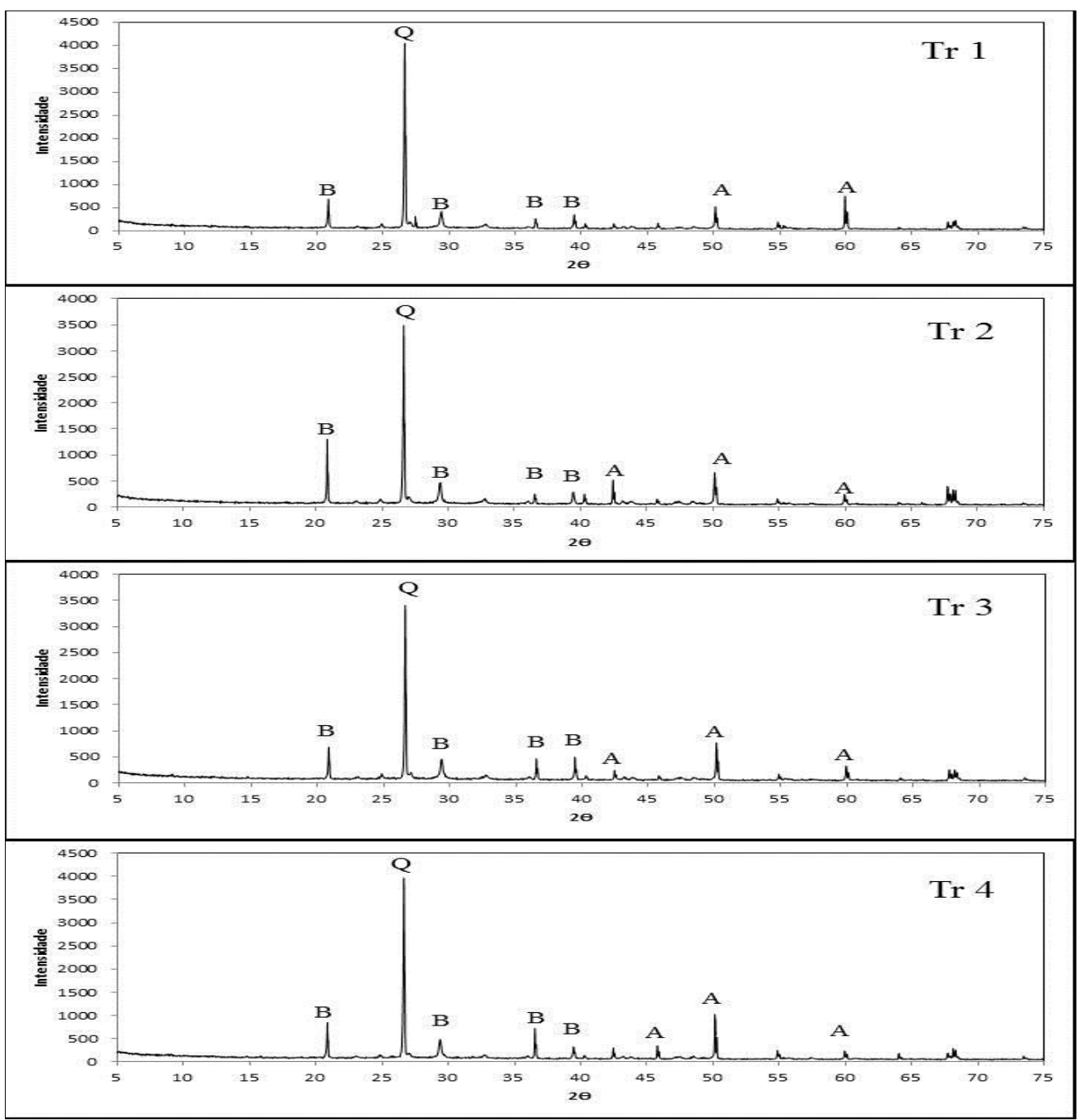

\section{CONCLUSÃO}

Os resultados apontaram que a utilização do resíduo da construção civil e de cinza volante se configura como uma boa alternativa de reaproveitamento de matéria reciclada para a produção de argamassas de baixo custo. É evidente que para os traços 3 e 4 com 10, 15\% em peso de cinza volante, a microestrutura da argamassa se comporta como aglomerante e pode ser perfeitamente utilizada para argamassa de assentamento e reboco em diversas aplicações de construção civil. 


\section{REFERÊNCIAS}

Associação Brasileira de Normas Técnicas, NBR 7211: Execução de revestimento de paredes e tetos de argamassas inorgânicas - Procedimento. Rio de Janeiro, 2005.

Associação Brasileira de Normas Técnicas, NBR 7215: Cimento Portland - Determinação da resistência à compressão. Rio de Janeiro, 1996.

Associação Brasileira de Normas Técnicas, NBR 7217: Determinação de composição granulométrica dos agregados. Rio de Janeiro, 1982.

Associação Brasileira de Normas Técnicas, NBR 9778: Argamassa e concreto endurecidos Determinação da absorção de agua por imersão, índice de vazios e massa especifica. Rio de Janeiro, 1987.

Associação Brasileira de Normas Técnicas, NBR 11578: Cimento Portland Composto. Rio de Janeiro, 1991.

Associação Brasileira de Normas Técnicas, NBR 13280: Argamassa para assentamento e revestimento de paredes e tetos - Determinação da densidade de massa aparente no estado endurecido. Rio de Janeiro, 1995.

CARVALHO, R. N. F. M.; CASTRO, K. F.; GONÇALVES, S. G; BESSA, B. T.; SOUZA, J. A. S. QUARESMA, D. S. Sustentabilidade na construção civil:Reaproveitamento de rejeitos argilo-minerais da construção civil para produção de argamassas. $57^{\circ}$ Congresso Brasileiro de Cerâmica e $5^{\circ}$ Congresso Íbero-Americano de Cerâmica, 2013, Natal/RN.

CURTIUS, A. J.; FIEDLER, H. D. Análise de metais e qualidade analítica. Meio ambiente e carvão: impactos da exploração e utilização. Porto Alegre: FEPAM, 2002. p. 211-227.

FERREIRA, K. C. Estudo dos parâmetros físico-químico para produção de argamassas utilizando resíduos industriais e da construção civil. Dissertação de mestrado (mestrado em Engenharia Química) - Programa de Pós-Graduação em Engenharia Química, Universidade Federal do Pará, 2014.

POZZOBON, C.E. Aplicações tecnológicas para cinza do carvão mineral produzida no complexo termelétrico Jorge Lacerda. Dissertação (mestrado em engenharia civil) - programa de Pós Graduação em engenharia civil, Universidade Federal de Santa Catarina, Florianópolis, 1999.

SIQUEIRA, J.S. de. Reaproveitamento de cinzas de carvão mineral na formulação de argamassas. Cerâmica 58 (2012) 275-279. 